\title{
Impact property of jute fabric reinforced PLA composites
}

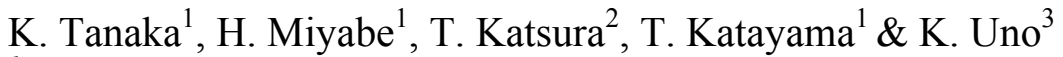 \\ ${ }^{1}$ Department of Biomedical Engineering, Doshisha University, Japan \\ ${ }^{2}$ Department of Mechanical Engineering, Doshisha University, Japan \\ ${ }^{3}$ Marubeni Co., Ltd., Japan
}

\begin{abstract}
In recent years, due to the increasing of the environmental issues, biodegradable polymers, especially PLA, have attracted attention. However, their applications are limited because the impact resistance and heat resistance of PLA are lower than those of the petroleum-derived resin. The impact resistance of PLA has been the subject of research and development in injection-moulding, which can be achieved by combining PLA and short natural fibre together. However, the impact resistance of PLA has not risen sufficiently, thus reinforcement of PLA by continuous fibre is expected. A FRTP high speed compression moulding method using the electromagnetic induction heating system, in which it is possible to control the temperature of the mould surface, is proposed and high speed forming of FRTP using continuous fibre becomes possible. However, the impact resistance of PLA reinforced by jute continuous fibre has not been studied yet. In this study, jute continuous fibre reinforced PLA was moulded by the FRTP high speed compression moulding method, using an electromagnetic induction heating system. The effect of nucleating agents and the annealing process on their impact properties were investigated. Since this system allows control of the temperature of the mould surface, it is able to perform an annealing process during the moulding process. In this study, jute continuous fibre and PLA with a nucleating agent were used to develop high impact resistance FRTP. The impact property of JFRTP is discussed.
\end{abstract}

Keywords: green-composite, jute fibre reinforced thermoplastics (JFRTP) natural fibre, jute fibre, PLA, non-woven fabric, electromagnetic induction. 


\section{Introduction}

Fibre reinforced plastics (FRPs) have been widely used in many applications, such as railway vehicles, automobile and airplanes, due to their excellence in formability and good mechanical properties [1-5]. Conventional fibre reinforced plastics cannot be biodegradable and they have the problem of being combustible [6]. In recent years, green-composite, the natural fibre reinforced biodegradable polymer, has attracted attention [7]. For the reinforcement of the green composite, natural fibres, such as bamboo fibre, ramie, flax, kenaf and jute, are used. Among these natural fibres, jute is one of the superior materials due to its low cost, large amount of production and high specific strength, and has thus gained a lot of attention [8-11]. Polylactic acid (PLA) is usually used for the matrix of the green-composite, because of its high strength, rigidity, melting point and productivity in comparison with other biodegradable resins. However, PLA has not been widely used in automotive applications due to its low impact resistance [12]. The impact resistance of PLA has been the subject of research and development; the improvement of impact resistance can be achieved by the reinforcement by natural fibre. Particularly, it is preferable to use the continuous fibre as a reinforcement fibre. Moreover, there is a method of improving various characteristics with the rising of crystallinity degree of PLA by the nucleating agent and annealing process. However, the forming method that can effectively carry out the annealing process to natural fabric reinforced PLA has not been established. The annealing process of PLA has not been applied to natural continuous fibre reinforced PLA; this is due to the difficulty in controlling mould temperature during the annealing process. Our research team have developed the high-speed compression moulding process of fibre reinforced thermoplastics (IH system) by means of an electromagnetic induction heating system (Cage System $^{\circledR}$ ) [13]. This system allows heating and cooling of the mould surface instantaneously and the mould surface can be arbitrarily controlled, so this system can be used for the annealing process. The nucleating agent is added to this PLA to enhance crystallization and the annealing process is introduced to the moulding process. However, the influence of the annealing process on impact resistance has not been studied yet. In this study, jute continuous fibre and PLA with a nucleating agent were used to develop high impact resistance FRP. The impact property of JFRTP is discussed.

\section{Materials and experimental procedure}

\subsection{Material}

Jute plain fabric $\left(0^{\circ} / 90^{\circ}\right.$, Fig. 1$)$ with the weight per unit area of $370 \mathrm{~g} / \mathrm{m}^{2}$ was used in this study. Polylactic acid (Cargill Dow LLC) with a nucleating agent (CPLA) was used for the matrix. It was melt-blown to a non-woven fabric (Kuraray Co. Ltd, Fig.2) in the weight per unit area of $50 \mathrm{~g} / \mathrm{m}^{2}$. In this study, the fibre volume fraction of the specimens was set at $50 \%$. The thickness of the specimens 


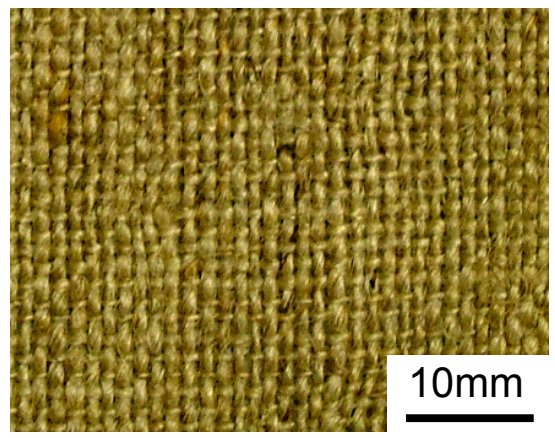

Figure 1: Jute plain fabric.

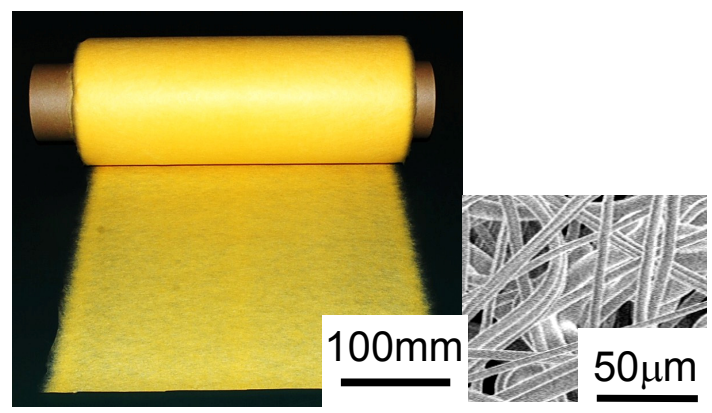

Figure 2: C-PLA non-woven fabrics.

was set at $2.8 \mathrm{~mm}$. To compare the impact properties of the JFRTP composite and the matrix resin, a C-PLA specimen was moulded with an injection moulding machine (ET-40v, Toyo machinery \& metal Co., Ltd).

\subsection{Mould process}

Specimens were moulded by the high-speed compression moulding method (to be referred to as the $\mathrm{IH}$ system) using an electromagnetic induction heating system (Roctool Co. Cage System ${ }^{\circledR}$ ). Fig. 3 shows the mould for the IH system [14]. When an electrical current runs through an inductor, a magnetic field is generated. This magnetic field penetrates the mould placed inside the inductor, and creates induced currents on the mould surface. Since the current flow concentrates within the mould surface by the shin effect, only the mould surface is heated by the Joule effect. The mould surface is cooled by cooling water flowing through pipes located directly under the mould surface. The traditional hot press method heats up the mould completely, while the IH system heats up only the mould surface. As a result, the thermal capacity decreases and the IH system allows cooling of the mould surface instantly. The heating process completes in only 40 seconds from $50^{\circ} \mathrm{C}$ to $190^{\circ} \mathrm{C}$. If an electrical current supplied by the coil is adjusted properly, the temperature of the mould surface 
can be controlled easily. Moreover, the annealing process can be carried out easily, and the overall moulding time, including the annealing process, is shortened.

\subsection{Moulding condition}

The moulding conditions of the specimens are listed in Table 1. The moulding temperature was set at $190^{\circ} \mathrm{C}$ and the moulding pressure was set at $3 \mathrm{MPa}$. The temperature of the mould surface was heated up to $190{ }^{\circ} \mathrm{C}$ and maintained for 60 seconds, then cooled down to $50{ }^{\circ} \mathrm{C}$ for the $\mathrm{J} / \mathrm{C} 0$ specimen. For the $\mathrm{J} / \mathrm{C} 60, \mathrm{~J} / \mathrm{C} 120$ and $\mathrm{J} / \mathrm{C} 600$ specimens, the annealing process with the crystallinity temperature at $100{ }^{\circ} \mathrm{C}$ was introduced after the moulding process. Fig. 4 shows an example of the temperature history of the mould surface during the moulding and annealing process.

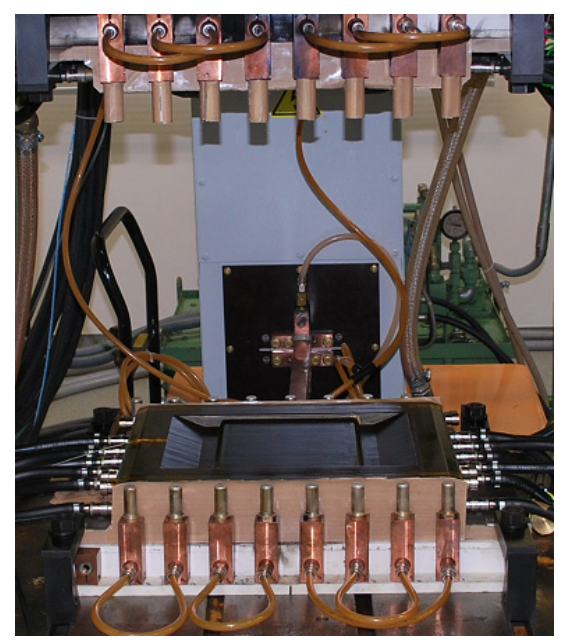

Figure 3: $\quad$ Mould for the IH system (Cage system ${ }^{\circledR}$ Roctool Co.).

Table 1: $\quad$ Moulding conditions.

\begin{tabular}{|c|c|c|c|c|c|}
\hline Specimens & $\begin{array}{c}\text { Moulding } \\
\text { pressure } \\
\text { (MPa) }\end{array}$ & $\begin{array}{c}\text { Temperature } \\
\left({ }^{\circ} \mathrm{C}\right)\end{array}$ & $\begin{array}{l}\text { Holding } \\
\text { Time } \\
\text { (s) }\end{array}$ & $\begin{array}{c}\text { Annealing } \\
\text { temperature } \\
\left({ }^{\circ} \mathrm{C}\right)\end{array}$ & $\begin{array}{c}\text { Annealing } \\
\text { time(s) }\end{array}$ \\
\hline $\mathrm{J} / \mathrm{CO}$ & \multirow{4}{*}{3} & \multirow{4}{*}{190} & \multirow{4}{*}{60} & \multirow{4}{*}{100} & 0 \\
\hline $\mathrm{J} / \mathrm{C} 60$ & & & & & 60 \\
\hline $\mathrm{J} / \mathrm{C} 120$ & & & & & 120 \\
\hline $\mathrm{J} / \mathrm{C} 600$ & & & & & 600 \\
\hline
\end{tabular}




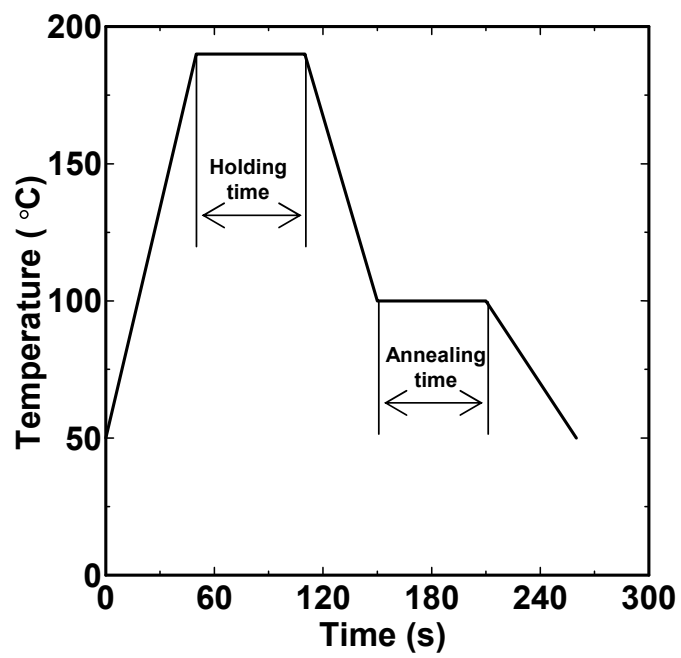

Figure 4: Temperature history of the mould surface.

\section{Mechanical testing}

\subsection{Impact test}

A Charpy impact test was conducted with a pendulum of 4.9J energy. The test specimens were cut out from the moulded parts using the water jet technique. The length and width of the specimens are $70 \mathrm{~mm}$ and $10 \mathrm{~mm}$ respectively. The support span of the specimens was set for $40 \mathrm{~mm}$ and the unnotched specimens were used.

The crystallinity degree of the PLA was measured by a Differential Scanning Calorimeter (DSC-60, Shimadzu Co.). The dynamic measurements were made at a constant heating rate of $10^{\circ} \mathrm{C} / \mathrm{min}$ to $200{ }^{\circ} \mathrm{C}$. The crystallinity degree of PLA was calculated by the following equation.

$$
X c(\%)=\frac{\Delta_{H}}{94} \times 100
$$

Cross sections and fractured surfaces of the specimens were observed by SEM (JSM-6390LT, JEOL Ltd.) in order to investigate the resin impregnation and fracture morphology. The void content of the specimens was measured by X-ray $\mu$ CT (SMX-160CTS, Shimadzu Co.).

\subsection{Three-point bending test}

Three-point bending tests were conducted by a universal material testing machine INSTRON 5566, following the recommended testing procedures as described in JIS-K7017. The test specimens were cut out from the moulded parts using the water jet technique. The length and width of the specimens are $60 \mathrm{~mm}$ and $15 \mathrm{~mm}$ respectively. The support span of the specimens was set for $40 \mathrm{~mm}$. 
Load was applied to the specimens at a displacement rate of $0.02 \mathrm{~mm} / \mathrm{sec}(1$ $\mathrm{mm} / \mathrm{min}$ ).

\section{Results and discussion}

\subsection{Impact property}

Fig.5 shows the results of the impact test for jute/C-PLA composites and C-PLA. Considering the fact that the impact resistance of the $\mathrm{J} / \mathrm{C} 0$ composite is higher than the impact resistance of C-PLA, the reinforcement by jute fibre increases the impact resistance. Moreover, the impact resistance of jute/C-PLA composite increased drastically when it is at 120 seconds of annealing time. Therefore, it is considered that the annealing time had influenced the impact resistance of the jute/C-PLA composite.

Fig.6 shows the relationship between the annealing time and crystallinity degree of C-PLA. Fig.7 shows the relationship between the crystallinity degree of C-PLA and the impact resistance of jute/C-PLA composites. As the annealing time becomes longer, the impact resistance and the crystallinity degree of C-PLA become higher. The fractured surface of the $\mathrm{J} / \mathrm{C} 0$ specimen observed by SEM is shown in Fig.8. Pull-out of the fibre bundle was observed and pulled out fibre bundles were observed for all other specimens moulded by different conditions. Cross sections of the specimens observed by SEM are shown in Fig.9. A lot of void was observed in specimens $\mathrm{J} / \mathrm{C} 0$ and $\mathrm{J} / \mathrm{C} 60$. However, void was hardly observed in $\mathrm{J} / \mathrm{C} 120$ and $\mathrm{J} / \mathrm{C} 600$. It is considered that void is caused in the cooling stage, due to the contraction percentage of jute fibre and PLA being different. Fig.10 shows the results of the void fraction for jute/C-PLA composites. The void contents of $\mathrm{J} / \mathrm{C} 60$ and $\mathrm{J} / \mathrm{C} 0$ are $6.3 \%$ and $6.4 \%, \mathrm{~J} / \mathrm{C} 120$ and $\mathrm{J} / \mathrm{C} 600$ are

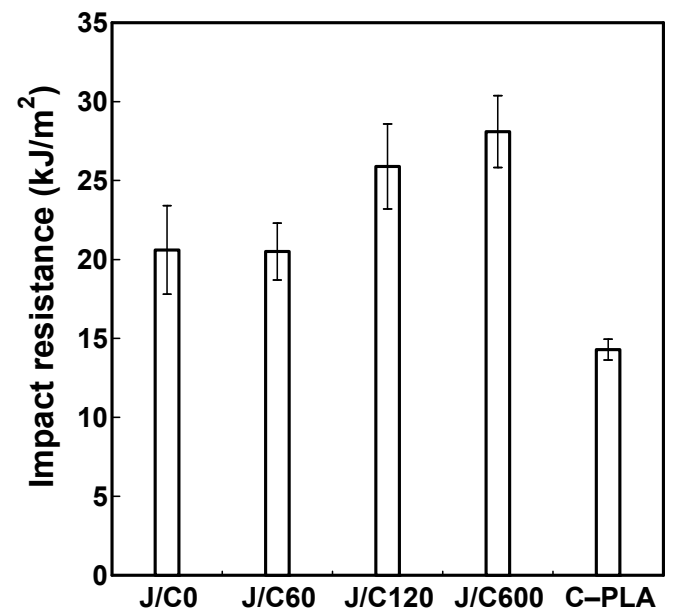

Figure 5: $\quad$ Impact resistance of JFRTP and C-PLA. 
relatively small, showing from 2 to $4 \%$. When the annealing time becomes longer, void content decreases as the pressure is applied during the cooling and the annealing time. The contact area of the fibre bundle and the resin increases when the void rate becomes small. Since the frictional drag increases when the fibre bundle is pulled out, it is considered that the absorption energy increases for specimens with longer annealing time.

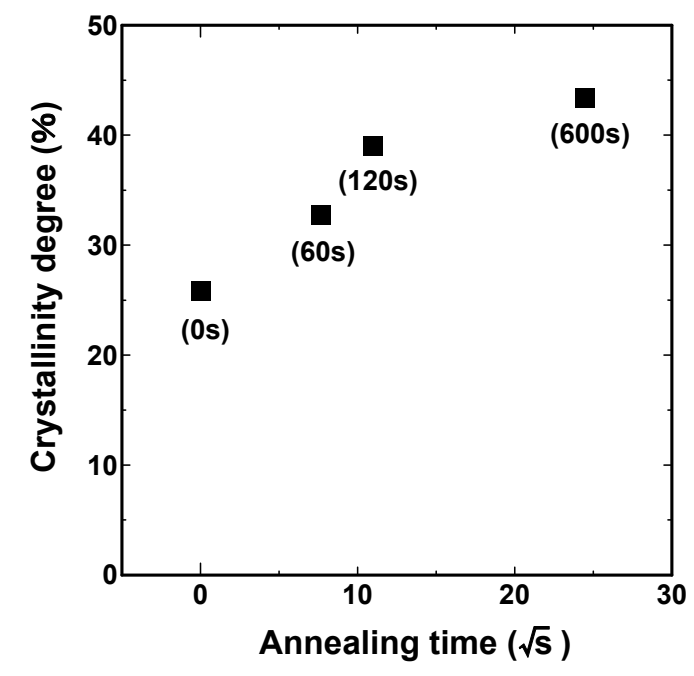

Figure 6: Relationship between annealing time and crystallinity degree.

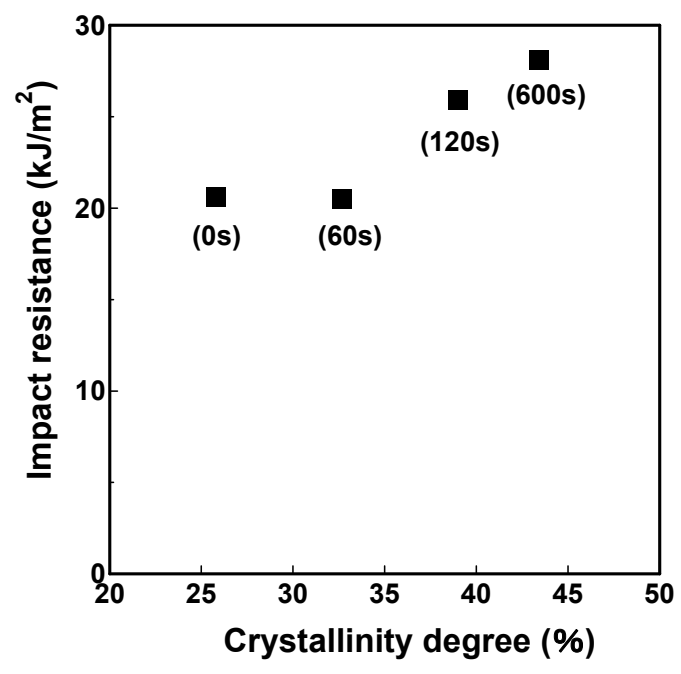

Figure 7: Relationship between crystallinity degree and impact resistance. 


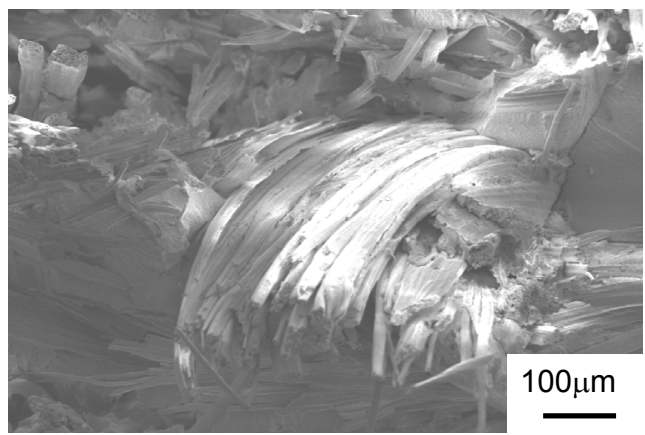

Figure 8: $\quad$ SEM observation of the fractured surface.

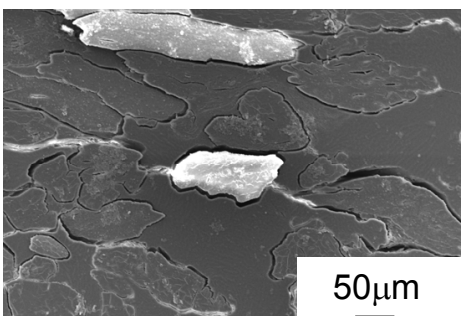

(a) $\mathrm{J} / \mathrm{C} 0$

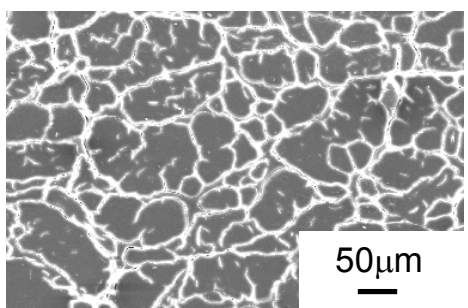

(c) $\mathrm{J} / \mathrm{C} 120$

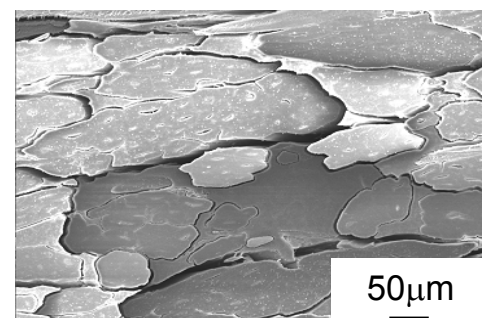

(b) $\mathrm{J} / \mathrm{C} 60$

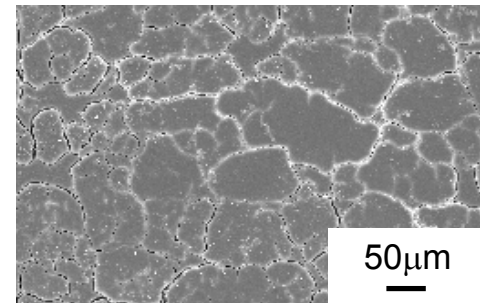

(d) $\mathrm{J} / \mathrm{C} 600$

Figure 9: $\quad$ SEM observation of the cross section.

\subsection{Bending property}

Fig.11 shows the bending strength for the jute/C-PLA composite obtained by a three-point bending test. The bending strength of the jute/C-PLA composite is higher than the bending strength of C-PLA due to its reinforcement by jute fibre. Fig.12 shows the load-displacement curves of jute/C-PLA and C-PLA. The bending moduli of $\mathrm{J} / \mathrm{C} 0$ and $\mathrm{C}-\mathrm{PLA}$ are $5.5 \mathrm{GPa}$ and $2.9 \mathrm{GPa}$ respectively. The bending modulus of jute/C-PLA was enhanced by fibre reinforcement. 


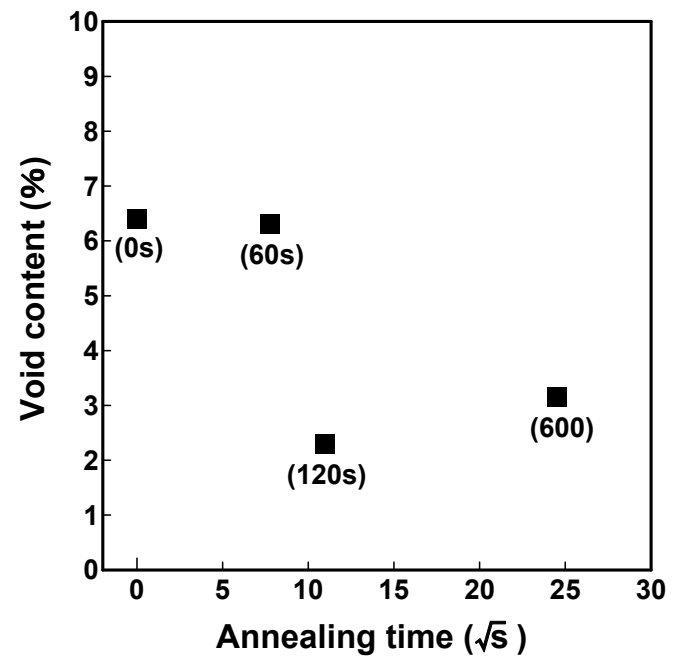

Figure 10: Relationship between annealing time and void content.

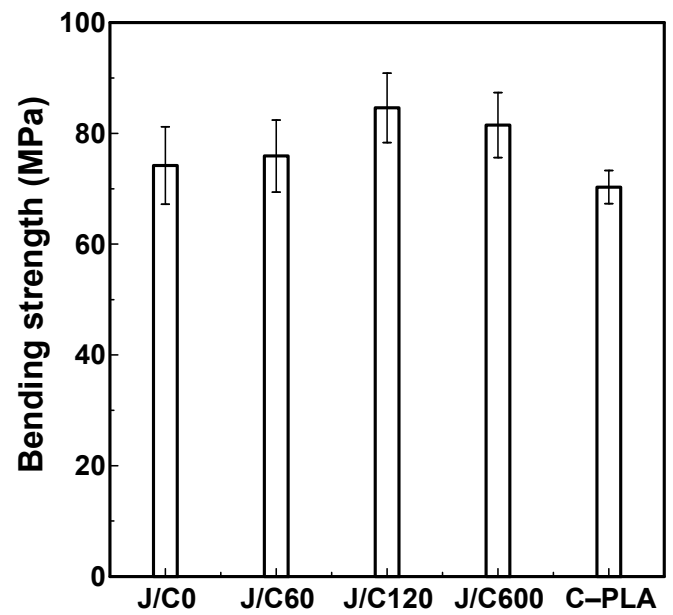

Figure 11: Bending strength of JFRTP and C-PLA. 


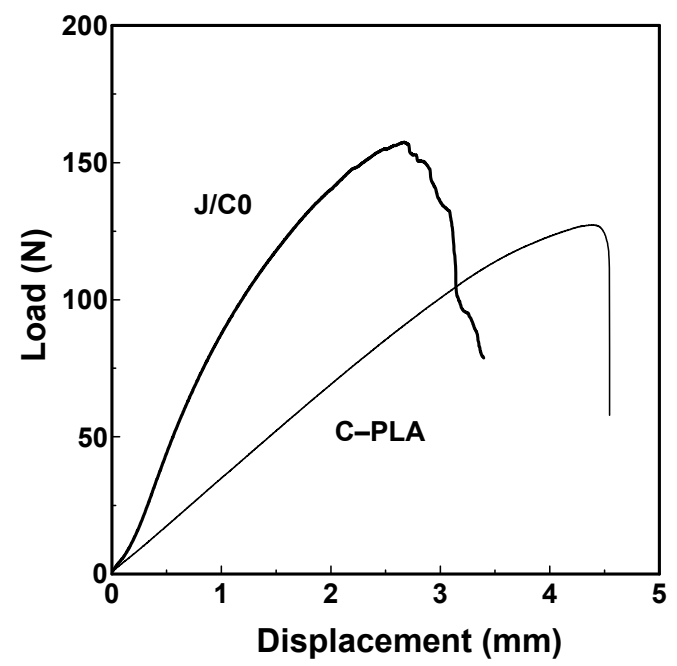

Figure 12: Load-displacement curves of JFRTP and C-PLA.

\section{Conclusions}

In this study, jute continuous fibre and PLA with a nucleating agent were used to develop high impact resistance JFRTP. The impact property and bending property of JFRTP were discussed. The investigation yields the following conclusions:

1. As the annealing time become longer, the crystallinity degree of C-PLA has improved.

2. As the annealing time becomes longer, the impact resistance of JFRTP has improved, due to the smaller void content.

3. The impact resistance and bending modulus of C-PLA have improved by reinforcement of jute continuous fibres.

\section{Acknowledgement}

This study was partially supported by the High technological research project on "Research and Development Center for Advanced Composite Materials" of Doshisha University and Ministry of Education, Culture, Sports, Science and Technology, Japan.

\section{References}

[1] P. Savignard, T. Bounit, Aerospace is reaching new altitudes with composites, Jec-composites magazine, 32, 40-41(2007). 
[2] P. V. Dine, J. Hall, K. L. Koudela, and G. Dillon, Composite marine impellers, Manufacturing Technology Development, Sampe journal, 42(4), 33-43(2006).

[3] J. Bruno Monteil, The European automotive industry will use more and more composites Jec composites magazine, 34, 24-26(1998).

[4] P. Feraboli, A. Masini, Composites part B engineering, 35, 323-335(2003).

[5] H. Nomoto, Railway vehicle, Reinforced plastic, 51(5), 227-233 (2005).

[6] H. Ikada, Degradable Plastic, 109-126(1990).

[7] T. Kimura, Natural Fiber Reinforced Eco-Composites (Aim at Environment Friendly Composites), Journal of the Society of Materials Science, 50(10), 1158-1163(2001).

[8] D. Plackett, T. L. Andersen, W. Batsberg and L. Nielsen, Biodegradable composites based on 1-polylactide and jute fibres, Composites science and technology, 63, 1287-1296(2003).

[9] C. Scarponi, Industrial applications for natural-fibre-reinforced composites, Jec magazine, 46, 46-48(2009).

[10] K. Oksman, M. Skrifvars and J.-F. Selen, Natural fibres as reinforcement in polylactic acid (PLA) composites, Composites Science and Technology, 63, 1317-1324(2003).

[11] M. Murariu and P. Dubois, The "green" challenge: high-performance PLA (nano) composites, Jec composites magazine, 45, 66-69(2008).

[12] H. Kawamoto, Development in Composites Technology for Reduction of Environmental Load, Journal of the Society of Materials Science, 57(10), 1067-1073 (2008).

[13] K. Tanaka, T. Katayama and K. Uno, Eco-efficient Manufacturing Process of Fiber Reinforced Thermoplastic, High performance Structures and Materials IV, WIT Transactions on the Built Environment, 97, 203210(2007).

[14] K. Tanaka, N. Kohashi, Y. Kinoshita, T. Katayama and K. Uno, Compression Molding of Carbon Fiber Reinforced Thermoplastics Using Non-Woven Stitched Multi-Axial Cloth by Means of Induction Heating System", Journal of Society Material Science, 58(7), 642-648(2009). 